\title{
A framework for the use of competencies for achieving competitive advantage
}

\author{
Terry Meyer* \& Paul Semark \\ Graduate School of Business Administration, University of the Witwatersrand, P.O. Box 98, Wits, 2050 Republic of South Africa
}

Received July 1996

\begin{abstract}
Competency, its nature, its acquisition and its maintenance, is emerging as the pivotal dimension of human development for employability, corporate competitive advantage and national economic success. It is. however, a concept still fogged by misunderstanding and debate. The authors of this article attempt to clear the fog by providing a succinct conceptual framework which integrates the contributions of many theorists and accommodates the use of the term in a variety of contexts. In addition, they propose that competencies are more than the essence of a national qualifications framework, or of corporate training programmes, as they are intimately linked to strategy with all its implications. Competency, therefore, is a central issue for managers seeking competitive advantage.
\end{abstract}

*Author to whom correspondence should be addressed.

\section{Introduction}

Competencies are the focus of attention of researchers and practitioners from a variety of disciplines and perspectives. A review of the literature shows that thinking surrounding the notion is far from uniform and that the term has different meanings in widely different contexts. The concept of an organization's core competencies is used in strategy to identify the fundamental features of the firm's competitiveness. Supporting the concept of core competence is that of strategic capabilities which are considered essential if firms are to leverage corporate resources effectively.

In the domain of management development, considerable controversy still exists between the United Kingdom based Management Charter Initiative (MCI) approach to defining national management competency standards and those supporting a flexible, organization specific approach to management competency development. In the field of vocational education and training, the National Vocational Qualification (NVQ) and General National Vocational Qualification (GNVQ) systems in the United Kingdom including the Scottish NVQ approach, and the Australian and New Zealand Qualification Framework, are becoming international models. South Africa is following fast with the development of its own National Qualifications Framework. Such systems, however, have been unable to address many of the fears of educationalists concerned with flexibility and the excellence of provider institutions.

At an individual level, the importance of generic meta-competencies as a pre-requisite for effective functioning in a modern economy is receiving considerable attention from learning specialists and industrial psychologists. In addition, the linkages between competencies and other factors of human performance such as values, personality, and culture, need to be researched.

Common to all approaches are a number of specific issues such as assessment, relevance over time, linkages to other socio-technical systems in an organization and methodologies for identifying competencies.

Of particular importance is the identification and definition of national competencies, especially for developing nations. Little is available in the current literature to guide decisionmakers and it is the authors' view that further investigation into the issue is essential.
The purpose of this article is to explore the notion of competencies and to provide a framework for contextualizing any particular approach at various levels. General issues relating to competence are then discussed and a conceptual model for linking many of the components underpinning performance is suggested.

\section{Framework}

A conceptual framework is proposed consisting of four categories, from national to individual. Each level of competency has a linkage to an external driver as shown in Figure 1.

The value of the framework lies in being able to position different approaches to competency in the appropriate context. It also demonstrates the linkages between categories. Hence organizational core and strategic competencies provide a context for occupational competencies and generic metacompetencies underpin specific occupational competencies, both vocational and managerial. Each category and its specific context is discussed below.

\section{National competencies}

Very little has been published relating to the concept of national competencies. However, global competitiveness centralizes the issue of national competencies, both as a means of underpinning domestic economic development, and as a factor in the investment decisions of multi-national corporations. It moves policy beyond simply producing a trained and educated workforce to the need for a strategic focus for education and training policy and linkages to economic and

\begin{tabular}{|c|c|c|}
\hline Category & Sub-category & External driver \\
\hline National competencies & & $\begin{array}{l}\text { National economic } \\
\text { strategy }\end{array}$ \\
\hline $\begin{array}{c}\text { Organizational } \\
\text { competencies } \\
\downarrow\end{array}$ & $\begin{array}{l}\text { - core } \\
\text { - strategic }\end{array}$ & Corporate strategy \\
\hline $\begin{array}{c}\text { Occupational } \\
\text { competencies } \\
\uparrow\end{array}$ & $\begin{array}{l}\text { - vocational } \\
\text { - managerial }\end{array}$ & $\begin{array}{l}\text { Individual career } \\
\text { management }\end{array}$ \\
\hline Generic individual & $\begin{array}{l}\text { - meta-compe- } \\
\text { tencies }\end{array}$ & $\begin{array}{l}\text { Personal motivation } \\
\text { and ability }\end{array}$ \\
\hline
\end{tabular}

Figure 1 Proposed framework 
development strategy. While the concept may be of less importance to developed economies, it is essential to developing economies which are dependent on targeting niche markets and external multi-national investment.

As many developing economies are moving from an agroindustrial base through various stages of manufacturing technology to information technology and service industry bases, the essential national competencies need to evolve accordingly. Malaysia is moving rapidly from a commodity dependent economy, based on rubber and palm oil production, through increasingly advanced stages of consumer goods manufacturing to hi-tech manufacturing. Their 2020 vision clearly links this economic strategy to human resources development strategies. Singapore is ahead in the cycle, with the vision of an 'intelligent island' by the year 2000 and dominance of tourism management in the region. Most of the Asia Pacific countries are at one or multiple stages in this evolutionary process.

National competencies can be defined as the cluster of competencies developed around strategic industries in a particular country. Historically, the Swiss watch-making industry grew a competency cluster through tradition which ensured that the knowledge, skills and craft culture were available to underpin innovation and state-of-the-art technology for that industry and its peripheral industries. With the accelerated pace of international competition, however, the needs for current and future strategic competencies must be reflected in the formal educational, training and R\&D centres of excellence supported by the industry and government. Hence in Singapore, one finds centres of excellence geared towards hi-tech electronics, bio-technology, entrepreneurship and tourism based on defined long-term economic policy. India is developing a key strategic competence in software programming and Malaysia has facilitated the establishment of a hi-tech academy in Penang by private sector firms including Motorola and Intel to support its drive towards hi-tech manufacturing. Many countries use their clusters of national competencies for offshore expansion: Singapore exports tourism to the region; the United Kingdom and Australia export expertise in education; the South African mining industry is clearly focussed elsewhere in Africa and internationally.

From a slightly different perspective, an additional opportunity for leveraging national competencies can be found through the application of a country's skills internationally. The offshore Chinese, for example, constitute the world's third largest economy and a considerable amount of earnings are reinvested in mainland China. Philippino crews are found serving on shipping lines throughout the world. Increasingly the labour market is becoming boundaryless, with countries reaping the benefit of their competitive competencies being applied offshore.

It is clear that national competency building in a fast changing global economy cannot be left to chance. While natural market forces will undoubtedly cause them to emerge over time, they provide a competitive opportunity to be actively leveraged. Such competencies need to be defined and developed proactively as prerequisites for the development of competitive industries, using international benchmarking to ensure world class practice. It is in this manner that national economic and development policy and national education and training policy become integrated.

The concept of strategic national competencies can be expanded to the regional level where competitive advantage can be gained through developing competency clusters in line with local economic advantages. Examples in the Southern African region would include tourism and a variety of infrastructural sectors such as transport, electrification and water management.

\section{Organizational competencies}

At an organizational level, two types of organizational competency are identified: core and strategic.

The idea of organizational core competence is forming the basis for strategic direction and organizational design. As popularized by their influential article in 1990 in the Harvard Business Review, Prahalad \& Hamel (1990) define organizational core competence as the combination of individual technologies and production skills that identify a company's myriad product lines'. Snyder \& Ebeling refer to

'tangible value added activities that are performed more effectively and at lower cost than that of the competition. These unique and enduring activities constitute a firm's core competence' (1992).

Hence core competence is recognized as the competitive advantage gained from 'a capability which lies behind the products that serve the market' (Tampoe, 1994). An example frequently quoted is Honda's production of reliable, small engines. This has enabled the company to expand its product range from motorcycles to a variety of other applications such as law/ı mowers, pumps and small cars. Sony has similarly exploited miniaturization for a variety of applications.

According to Tampoe (1994) core competencies differ from other organizational features such as distinctive capabilities, end products and core businesses, in that these can be imitated and are vulnerable over time. He proposes the following characteristics:

- essential to corporate survival in the short and long term

- invisible to competitors

- difficult to imitate

- unique to the corporation

- a mix of skills, resources and processes

- a capability which the organization can sustain over time

- greater than the competence of an individual

- essential to the development of core products and eventually to end products

- essential to the implementation of the strategic vision of the corporation

- essential to the strategic decisions of the corporation for example diversification, downsizing, joint ventures, etc.

- marketable and commercially viable

- few in number

He includes competence in a formula showing the components of sustained profitable growth as:

'Sustained Profitable Growth $=$ (core competence of $\mathrm{CO} \times$ shared strategic vision $\times$ motivated organization $\times$ market leverage)' (1994).

Prahalad conceptualizes core competence as:

'Competence $=($ Technology $\times$ Governance $\times$ Collec tive Learning)'(1993). 
Core competence, therefore, is an aggregate of a number of things, tangible and less tangible. It includes the core technologies and processes resident in the organization as well as the occupational, technical, managerial and generic individual competencies of all the employees of the business which contribute in essential ways to its mission. It is the orchestration of these that provides the value added to individual performance, however, and hence the firm's competitive advantage.

Related, but conceptually different, are strategic competencies or capabilities. These provide an organization with distinctive capability. Management systems, technologies, production processes or the systems necessary for mission achievement require competencies which are essential to simply compete in the market and which, when they are superior to others in the industry, provide a competitive advantage. By understanding the business processes and value chains, it is possible to map the strategic competencies which an organization requires and evaluate current competence against world class standards. Unlike core competence, strategic competencies can be imitated by competitors relatively easily and therefore they often change with changing technology, processes and business strategy. In addition to strategic competencies linked to business processes, there are strategic competencies which are contextual in nature. In the South African context, for example, strategic competencies must include those demanded by processes of participative management and stakeholder engagement.

Many joint ventures, takeovers and alliances are undertaken to enable organizations to acquire strategic capabilities (although Lei \& Slocum, 1993; and Login \& Young, 1994; warn of the dangers of such a strategy). Strategic recruitment is often needed to supplement existing competencies when new technologies or systems become necessary. Their identification, deployment and evaluation is therefore a key priority for management and cannot be devolved to a staff function within the human resources department or elsewhere in the organization. Not only are business strategy and focus essential, but they need to be reflected in the range of occupational and individual competencies possessed by members of the firm, weaving human resources development and competency development together into strategic value for the organization.

Gronhaug \& Nordhaug (1992) present a strategy for the development of organizational competencies (see Figure 2).

I. Estimation of future competency requirements

STRATEGY

2. Mapping and assessment of in-house competence

FORMULATION

3. Identification of competence gap

PROCESS

4. Plan for competence building

STRATEGY 5. Implementation of plan for competence building

IMPLEMENTATION 6. Utilization of competence

Figure 2 Strategy for developing organizational competence (Gronhaug \& Nordhaug, 1992)
Of importance in such a strategy is the multiple methodologies which can be used for competence building and acquisition. These could range from a merger or acquisition, to strategic recruitment or may involve a variety of learning processes.

Finally it must be emphasized that organizational competencies need to extend beyond simply the accumulation of individual competence. An essential feature of organizational competencies is that in addition to residing in individuals they are incorporated in the records, processes and technology of an organization. An important exercise for any organization is to establish where its core and strategic competencies are located and ensure that they are institutionalized since individuals and their personal intellectual capital can walk out at any time.

\section{Occupational competencies}

The proposed framework refers to occupational competencies as those which are necessary to perform in a particular occupational or other role. As such they are linked to an occupation or profession which is generally underpinned by a defined body of knowledge, skills and values. In this context management is seen as an occupation since managers have a particular role to play and managerial competencies have been defined which relate to such specific roles. However, it is acknowledged that managerial competence has unique features, including considerable disagreement in the literature about what constitutes management and managerial competence. For this reason it is treated as a distinct sub-set of occupational competence and is distinguished as a category from vocational competencies.

\section{Vocational competencies}

Vocational competencies refer to the technical competencies necessary to perform according to standards required by a job or occupation. Performance and the conditions or context in which they are expected to be demonstrated tend to be clearly defined. It is this approach which is adopted by the English NVQ and GNVQ systems, the Scottish NVQ system, the Australian and New Zealand Qualifications system and which will form the basis for the South African NQF. The key feature of the approach is that it is modular in nature and credit for demonstration of competence is given as a contribution to nationally recognized qualifications. These competencies are largely determined by relevant industry bodies and certification is not dependent on formal study or training.

Definitions vary. The definition proposed here is that competence is the demonstration of an integration of knowledge, skill, personal attributes and value orientation. There are a number of important concepts implied by this definition:

- performance needs to be demonstrated and therefore performance criteria and effective assessment mechanisms are an essential feature of vocational competencies;

- there needs to be an integration of knowledge, skill, personal attributes and value orientations;

- knowledge implies understanding and assumes that performance is underpinned by cognitive process skills which need to be understood and demonstrated; 
- skills are frequently perceived as referring to only observable psycho-motor skills but of course refer also to cognitive and conceptual skills;

- personal attributes include such constructs as personality and disposition which themselves are difficult to measure but which influence performance; and

- value orientation refers to the underpinning values which influence a person's behaviour or are necessary for effective performance within a vocational context.

At the lower levels in the skills continuum there appears to be almost universal acceptance of this approach. It is at the higher levels where agreement is less forthcoming, especially from the educational fraternity. It is at this level that the cognitive and affective domains of competency and situational relevance are of increasing importance and less easily defined.

Vocational competencies are, by definition, linked to occupations within or across industries and, in many cases, to specific jobs. To accommodate changes in technology, work practice and enterprise-specific requirements, however, it is considered preferable to identify these in terms of work processes and to cluster these to meet the needs of specific jobs in specific contexts. While vocational competencies are defined in terms of standards and key competencies necessary for specific occupations, there must be sufficient flexibility in the system to reflect strategic and even core organizational competencies at job level in specific enterprises. Where relevant occupational or industry competency standards do not meet such requirements, enterprise-defined competency standards should be registered for national recognition where they meet certain criteria.

\section{Management competencies}

It is in the area of defining managerial competencies that most controversy seems to arise. The two poles of the debate appear to be between those favouring the Management Charter Initiative $(\mathrm{MCl})$ in the United Kingdom, which attempts to define national competency standards for management which are related to the function of management beyond the individual in accordance with the NVQ approach, and those who believe that management competence, especially the leadership component of it, needs to be enterprise specific and is linked to individual abilities.

Wills (1993) provides a useful case both for and against the $\mathrm{MCI}$ approach in which he highlights the need for a flexible, holistic and situation specific approach to management competence. Turner \& Crawford (1995) make a distinction between operational and reshaping competencies. Within the context of management it is likely that many of the operational competencies of management are relatively static and definable in terms of, for example, an MCI approach. Reshaping competencies, concerned with transformation and creating the corporate future, are less likely to be definable since they are complex, relatively situational and conceptually abstract. It is here that the importance of individual meta-competencies, such as the ability to manage relationships and cognitive complexity, becomes apparent and it is the unique interaction of these meta-competencies and underpinning values which results in effectiveness.
Brown (1993) identifies two major American views of managerial competence. The American Assembly of Collegiate Schools of Business (AACSB), the major accrediting body for business schools, identifies a list of seven content categories of competence and nine skills and personal characteristics. The American Management Association (AMA) McBer approach provides five clusters of competence and a six-stage process for acquiring competence.

These tend to favour an attribute approach (that is competencies are inferred from individual behaviour) over the $\mathrm{MCI}$ performance approach (that is behaviour required for effective job performance is important and not the underpinning attributes).

While the literature and debate is extensive, one of the most useful recent publications on the issue contains the results of the Australian Industry Task Force on Leadership and Management Skills co-ordinated by David Karpin (1995). The research report provided by the group studying International Best Practice concluded that:

'Competencies seem to be most useful to enterprise management development when they are:

- determined by current and emerging business requirements

- based on successful management performance

- designed to be simple and easy to use

- associated with equally important key technical competencies

- developmentally oriented'.

Difficulties arise when attempting to develop national management competency standards because contextual issues are ignored. These contextual issues include:

- The developmental phase of an organization. Turner \& Crawford (1995) distinguish between reshaping and operational competencies. It follows that the competencies required for leading an organization through burning platform transformation, incremental change and consolidation phases of an organization's life cycle will be significantly different.

- The context of the team. Rosenbach (1995) points out that one cannot understand leadership without understanding followership and in particular the competencies of the immediate team in which the manager is operating.

- The context of the organization. Each organization has its own culture reflecting its own core competence. Different organizations and industries have different cultures and the ability to manage effectively in one may not be transferable to another.

- National context. The debate about whether international management practices are relevant in South Africa rages on. What is certain is that issues surrounding social culture, norms and practices are of particular influence in a multi-cultural environment like South Africa.

Unless managerial competencies are related to organizational core and strategic competencies their usefulness is limited, since it is current and future organizational strategy which provides the context and reference point for managerial capability and effectiveness. In a management/leadership environment characterized by complexity and rapid change, the distinction between managerial competencies and generic 
individual meta-competencies, including the ability to learn quickly, becomes vague.

\section{Generic individual meta-competencies}

It is clear from the literature that the debate between the job or performance-focussed approach, used largely in the context of NVQs, and the person-centred, attribute approach continues unabated. It is the authors' view that both approaches are useful in an appropriate context.

By generic, individual meta-competencies, we refer to those which transcend specific jobs but which are essential for effective functioning in a modern economy. While individual vocational competencies frequently have a relatively short life-cycle of relevance, meta competencies tend to be enduring and relevant throughout a persons life. It is becoming clear that in the modern world of work, individual selfmanagement or personal effectiveness competencies are increasingly important if individuals are to work effectively in teams and to manage themselves through boundary-less careers in relatively unstructured organizations.

Meyer (1995) identified the following generic competency clusters necessary to function effectively in the modern world of work:

- the ability to locate and interpret relevant information from written, electronic and human sources and apply it to solve complex, multi-dimensional problems using processes of analysis, synthesis and systemic thinking;

- the ability to communicate effectively with diverse groups of people and individuals on complex issues;

- the ability to apply scientific and mathematical concepts and use relevant technology effectively;

- the ability to innovatively apply knowledge and skills in changing situations and manage change effectively;

- the ability to operate effectively in multi-disciplinary teams;

- the ability to use time effectively to manage a variety of tasks; and

- the ability to manage one's own, often multiple career and balance occupational, family, community and other demands effectively.

The authors have identified clusters of meta-competencies which appear to capture the majority of individual competencies identified in the literature.

\section{Cognitive complexity}

The ability to manage different levels of cognitive complexity is described in the influential work by Eliot Jaques (1995) in his development of Stratified Systems Theory. Jaques identifies seven levels of cognitive complexity based on management discretion.

Procedures to assess individual levels of functioning have been used extensively in South Africa, Namibia and Botswana with repeatedly high levels of validity.

Numerous other techniques to measure conceptual reasoning or related cognitive capability are used internationally, including psychometric assessment, style inventories and assessment centres.

\section{Relationships}

Given the imperatives of being able to operate in teams, manage cultural diversity and be customer focussed, the ability to communicate and manage relationship is essential to the modern world of work. While there are numerous definjtions of competencies relating to managing relationships, three levels of relationship management can be identified:

- facilitating intra-team relations;

- facilitating inter-team organizational interfaces e.g. across functional boundaries; and

- facilitating external interfaces, that is with external stakeholders.

Facilitation is a competence which is essential to the modern world of work.

\section{Performance}

Performance competencies refer to the ability to operationalize ideas and innovation, that is to make things happen and have an impact on one's environment. Particularly important in this cluster of competencies would be those relating to change management at both a personal and organization level.

\section{Learning competencies}

Learning is essential if individuals are to compete effectively in modern society. The ability to deal with new knowledge, concepts, values and behavioural norms, both at a cognitive and affective level is essential in a continuously transforming organizational and societal context.

The work by Kolb, Mumford and others on learning style provides important understanding on how learning takes place at an individual level.

In today's information society, key competencies are those concerned with connecting information to knowledge and understanding the impact of new knowledge on individual performance.

The above competency categories are by no means mutually exclusive. Their usefulness is in providing a framework within which generic competencies can be identified and located in whatever way is useful to the user. Generic competencies, however, are applicable across all functional or occupational disciplines and all organizational or societal levels. As such, they are concerned with individual process management rather than content issues.

\section{Key issues in the competency debate Components of competence}

The proponents of the performance approach to competencies argue that any underlying factors influencing the performance of an individual are of little relevance to the demonstration of competence. What matters is whether performance meets predefined standards of competence.

To influence and contextualize the development of competencies, other approaches have attempted to identify the underlying component features of the notion. Semark (1995) argues that individual competency, like corporate competency, is a complex hierarchy of interrelated and interdependent factors and capabilities. He illustrates the interrelationship through use of a segmented cone constructed on the foundation of a mission, energized and channelled by a value system 
into achieving defined goals through specific outputs, given effect through knowledge and skills applied in a functional style. He describes the cone in the context of career development stating that: its growth and development in the world of work is the process of career development (see Figure 3).

Jaques (1995) suggests a formula for deriving current actual capacity as follows (see Figure 4).

Bloom's original typology identified three domains of competency, namely: psycho-motor; cognitive; and affective.

It is evident that common to most understanding of competence are: performance; knowledge and understanding; and a value orientation.

The above approaches to exploring and defining the underlying factors of competence provide useful insight into the nature of the concept. It is the way in which these variously defined constructs are incorporated into the identification, description and assessment of competence which warrants further research.

\section{Competency life cycles}

Ongoing, discontinuous change in respect of technology, organizational and work re-design and changing values im-

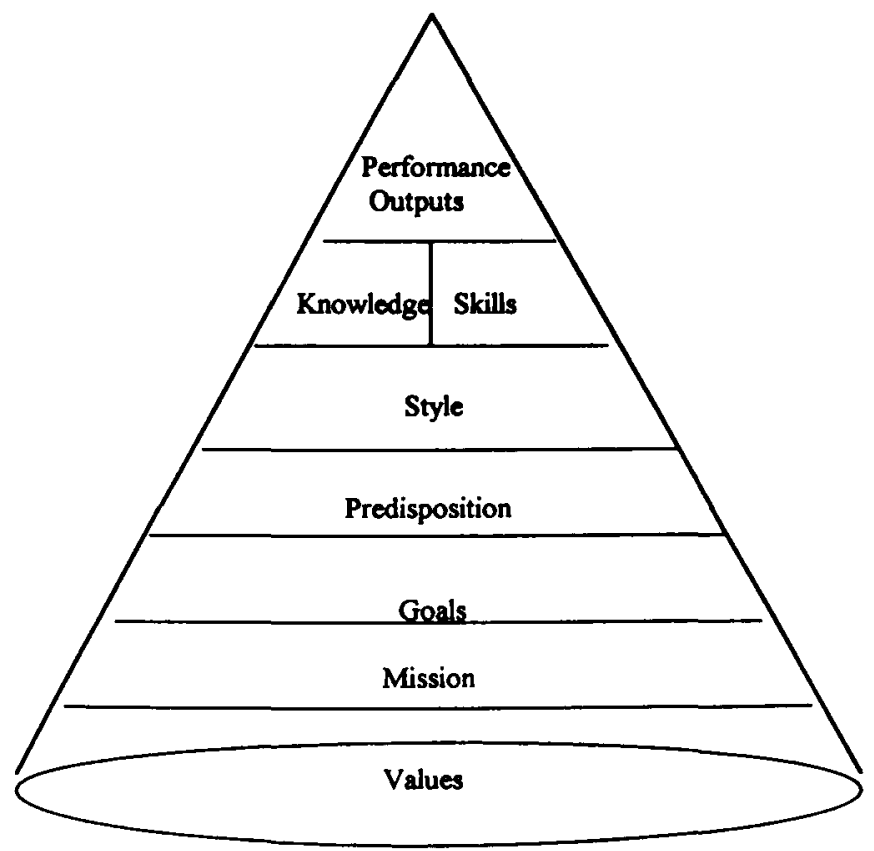

Figure 3 The competency cone

$$
\begin{array}{cl}
\begin{array}{cl}
\text { Cognitive power } \\
+
\end{array} & \begin{array}{l}
\text { (Cognitive complexity or innate mental ability to } \\
\text { organize information) }
\end{array} \\
\text { Kalues } & \quad \begin{array}{l}
\text { (Interests or priorities) } \\
+ \\
+
\end{array} \\
+ & \begin{array}{l}
\text { (About people and things) } \\
-T
\end{array} \\
& \begin{array}{l}
\text { (The absence of serious personality [temperament- } \\
\text { al] defects) } \\
\text { Current actual capacity }
\end{array}
\end{array}
$$
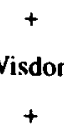

Figure 4 Current capacity formula, (Jaques, 1995). plies that many competencies have a useful life cycle. Turner \& Crawford state that

'If competence underlies competitive success, the rise and fall of different firms over time indicates that either competence possessed is often lost, or, the relevance of some particular competence to competitive advantage is not permanent' (1995: 8).

In respect of technological change, this is well illustrated in the computer industry, where competencies necessary for mainframe operations were superseded by the need for microcomputer and PC competencies which are currently being overtaken by the importance of system integration and network competencies.

In the South African context, many of the traditional quantitative managerial competencies are being superseded by the importance of communication and stakeholder or constituency management as pre-requisites for general management.

The capacity to update and form new market-relevant competencies is therefore central to continuous competitive success (Turner \& Crawford, 1995). This applies equally at national level, organizational level and occupational level. It underpins the importance of the concepts of the learning nation, the learning organization and life-long individual learning.

If the concept of competency life cycle is of such importance, how do individuals and organizations cope with changing requirements? McGrath, MacMillan \& Venkatarama (1995) identified comprehension and deftness as the two antecedents to emerging competence. They point out that in new, complex situations, comprehension of the variables and the relationship between them is seldom well understood and often based on assumptions. Processes within an organization can enhance or inhibit the development of comprehension and this is crucial to the development of competence. Deftness refers to the ability of an organization to manage efficiently the acquisition and sorting of necessary information efficiently. Both are considered integral parts of organizational learning processes necessary for competitive advantage.

Defillippi \& Arthur (1994) point out that at a person centred level of analysis, sequences of job opportunities go beyond the boundaries of simple employment settings. They term such career paths boundary-less careers and identify three career competencies necessary for effective boundaryless career management. These are:

- Know-why competencies which are concerned with career motivation, personal meaning and identification. Increasingly know-why competencies are relating to life planning and management and not only occupational career management.

- Know-how competencies which are relevant skills and knowledge necessary for individual marketability.

- Know-whom competencies which relate to the ability to manage career relevant networks.

It is clear that while national, organizational and occupational competencies which are largely 'content linked' have a life cycle within the context of change, individual meta competencies are more constant. The ability to manage cognitive complexity, relate effectively to people and learning new skills and competencies are process competencies under- 
pinning the ability of an individual, or collectively, an organization or nation, to survive change and develop the specific competencies necessary for competitive advantage and renewal.

\section{From task competence to innovation}

Competency based qualification systems are often criticized as being inflexible and mechanistic. The history of training in many South African organizations, especially at the lower levels, has resulted in a task focussed, behaviourist approach to competency development characterized by a dependence on task analysis, a fixation on need to know learning and the application of an 'if it can't be measured, it can't be taught' approach.

Such an approach is clearly unsuitable for a business environment characterized by changing work practices, new technology and demands for quality and customer focus. Organizations in this environment require individuals who are multi-skilled, able to understand and respond to new situations, able to solve problems and take correct decisions. These attributes need to be reflected in defined occupational competencies.

To be internationally competitive, however, the ability to respond to changes at a systemic level is not sufficient. What is required for world class performance is a level of competence where innovation is the norm.

Reagan (1994) demonstrates that organizational and individual competencies develop sequentially from least complex to most complex. Hence transformation is seen to move through three phases which he describes as:

- The ability to demonstrate core job requirements. This would equate to the ability to perform the behaviourally defined tasks which are core to the job.

- The ability to adapt to changing requirements. This would equate to contingency management in which changes within the system are tolerated and management would require an understanding of the broader system.

- The ability to anticipate and generate change. This would require a level of understanding of the system and the external context of the system enabling proactive and innovative change at a systemic level.

It is argued that most vocational qualification frameworks will at best address the need to manage change within the system through contingency management abilities. For individual or organizational competitiveness, a level of competence at a systemic level enabling innovation and change generation is necessary.

\section{Conclusion}

This article set out to explore the complex notion of competencies and to provide a framework for contextualizing any particular approach at various levels.

In discussing the framework, an attempt has been made to understand the context of each category of competence, the importance of each category to the external drivers and some of the key issues associated with it. It is argued that organizational core and strategic competencies provide the context for, and are reflected in, occupational competencies, whether vocational or managerial in nature. Similarly, occupational competencies are underpinned by various generic or meta- competencies which an individual needs to possess to operate in a modern economy.

The importance of competencies as a concept, is the centrality of knowledge, skills and abilities for national, organizational and individual competitiveness. Increasingly systems are being created to identify, acquire and assess the competencies which now and in the future will create competitive advantage. In the boundaryless world of the emerging global economy and universal availability of information, it is argued that competency at individual, organizational and national levels will become the currency of the 21 st Century.

\section{References}

Alderson, S. 1993. 'Reframing management competence: focusing on the top management team', Personnel Review, 22(6): 53-62.

Beamer, L. 1992. 'Learning intercultural communications competence', The Journal of Business Communication, 29(3): 284 303.

Best Practice Management and Leadership Development. Industry task force on leadership and management skills. Executive Summary.

Birkett, W.P. 1992. 'Question of competence', Australian Accountant, December: 58-59.

Brown, R.B. 1993. 'Meta-competence: a recipe for reframing the competence debate', Personnel Review, 22(6): 25-36.

Cannon, F. 1995. 'Developing competencies that drive business performance', Journal of Strategic Change, 4: 125-136.

Cappelli, P. \& Crockert-Hefter, A. 'Distinctive human resources are firms' core competencies', Organizational Dynamics, pp. 7-21.

Cofsky, K. 1993. 'Critical keys to competency-based pay', Compensation \& Benefits Review, November-December: 46-52.

Colquhoun, A. 1994. 'From professional conduct to professional competence', Accountancy, September: 75.

Corbett, C. \& Van Wassenhove, L. 1993. 'Trade offs? What tradeoffs? Competence and competitiveness in manufacturing strategy', California Management Review, Summer: 107-122.

Defillippi, R. \& Arthur, M. 1994. 'The boundaryless career: a competency-based perspective', Journal of Organizational Behaviour. 15: 307-324.

Dubois, D.D. 1993. Competency based performance improvement. HRD Press.

Garrick, J. \& McDonald, R. 1992. 'Competence standards for industry trainers: alternative models', Journal of European Industrial Training, 16(7): 16-20.

Gillin, P. 1994. Core competence. Computerworld, p.4.

Gonezi, A., Hager, P., Athanasou, J. 1993. The development of competency-based assessment strategies for the professions. Canberra: Australia Government Publishing Services.

Gonezi, A., Hager, P., Athanasou, J. 1994. Establishing competencybased standards in the professions. Canberra: Australia Government Publishing Services.

Gronhaug, K. \& Nordhaug, O. 1992. 'Strategy and competence in firms', European Management Journal, 10(4): 438-444.

Holmes, L. \& Joyce, P. 1993. 'Rescuing the useful concept of managerial competence: from outcomes back to process', Personnel Review, 22(6): 37-52.

Iles, P. 1993. Achieving strategy coherence in HRD through competence based management and organisation development', Personnel Management, 22(6):63-80.

Jaques, E. 1995. Executive leadership: a practical guide to management complexity. Blackwell.

Johnson, P., Smith, D. \& Smith, R. 1994. 'SPX adopts a strategy, quality, value model', Planning Review. January/February: 19-24. 
Karpin, D.S. 1995. Enterprising nation - renewing Australia's managers to me't the challenges of the Asis pacific century. Executive summary. Canberra: Australia Government Publishing Services.

Kozin, M. \& Young, K. 1994. 'Using acquisitions to buy and hone core competencies', Mergers \& Acquisitions, September/October: 21-26.

Lado, A. \& Wilson, M. 1994. 'HR systems and sustained competitive advantage: a competency-based perspective', Academy of Management Review, 19: 699-727.

Leblanc, B. 1994. 'European competencies - some guidelines for companies', Journal of Management Development, 13(2): 72-81.

Lei, D. \& Slocum, J. 1992. 'Global strategy, competence-building and strategic alliances'. California Management Review, Fall: 81 97.

MacMillan. I., Venkataraman, S. \& McGarth, R.G. 1995. 'Defining and developing competence: a strategic process paradigm', Strategic Management Journal, 16: 251-274.

Mansfield, B. 1993. 'Competence-based qualifications: a response', Journal of European Industrial Training, 17(3): 19-22.

Marquardt, M. \& Engel, D. 1993. 'HRD competencies for a shrinking world'. Training \& Development, May: 59-65.

McAuley, J. 1994. 'Fxploring issues in culture and competence', The Tavistock Institute, 47(4): 417-430.

Meyer, T. 1995. 'Competency controversy: which direction to follow?', People Dynamics, August: 23-26.

Meyer, T. 1995. Management competencies - a foundation for wisdom and innovation or expensive bureaucy. Unpublished Paper. Johannesburg: Wits Business School.

Mole, G., Plant, R. \& Salaman, G. 1993. 'Developing executive competences: learning to confront, confronting to learn', Journal of European Industrial Training, 17(2) 3-7.

Nemerov, D. 1994. 'How to design a competency-based pay program', Journal of Compensation \& Benefits, March-April: 46-53.

Pickett, L. 1995. Global competencies for workplace outcomes. Unpublished Paper. Australian Human Resources Insitute.

Prahalad, C. \& Hamel, G. 1990. 'The core competence of the corporation'. Harvard Business Review, May-June.

Prahalad, C.K. 1991. The role of core competencies in the corporation', Research Technology Management, pp. 40-47.
Reagan, P. 1994. 'Transform organizations using competency development', Journal of Compensation \& Benefits, March-April: 2531.

Rosenbach, W.E. \& Taylor, R.L. 1993. Contemporary tssues in leadership. Westview Press.

Rutherford, P.D. 1995. Competency based assessment. Melbourne: Pitmans Asis Pacific.

Semark, P. 1995. A competency approach to career pathing. Unpublished Paper. Johannesburg: Wits Business School.

Simonsen, P. \& Wells, C. 1994. 'African American take control of their careers', Personnel Journal, April: 99-108.

Smith, B. 1993. 'Build managers from inside out - develop managers through competency-based action learning', Journal of Management Learning, 12(1): 43-48.

Snyder, A. \& Ebeling jnr, H.W. 'Targeting a companys real core competencies', Journal of Business Strategy, pp. 26-32.

Stalk, G., Evans, P. \& Shulman, L. 1992. 'Competing on capabilities: the new rules of corporate strategy', Decoding the Business Logic, March-April: 19-39.

Stewart, J. \& Hamlin, B. 1992. 'Competence-based qualifications: the case of established methodologies', Journal of Eumpean Industrial Training, 16(10): 9-16.

Stewart, J. \& Hamlin, B. 1992. 'Competency-based qualifications: the case against change', Journal of European Industrial Training, 16(7) 21-32.

Tampoe, M. 1994. 'Exploiting the core competences of your organization', Long Range Planning, 27(4): 66-77.

Turner, D. \& Crawford. M. 1992. 'Managing current and future competitive performance: the role of competence'. Sydney: AusIralian Graduate School of Management, Centre for Corporate Change, pp. 1-26.

Vines, J. 1995. Enterprising nation: international best practice in leadership and management development. Canberra: Australia Government Publishing Services.

Wills, S. 1993. 'MCI and the competency movement: the case so far', Journal of European Industrial Training, 17(1): 9-11. 